Meta

Journal des traducteurs

Translators' Journal

\title{
MT Project at University of Innsbruck
}

\section{J. Wormwood}

Volume 37, numéro 2, juin 1992

URI : https://id.erudit.org/iderudit/004620ar

DOI : https://doi.org/10.7202/004620ar

Aller au sommaire du numéro

\section{Éditeur(s)}

Les Presses de l'Université de Montréal

ISSN

0026-0452 (imprimé)

1492-1421 (numérique)

Découvrir la revue

Citer cet article

Wormwood, M. J. (1992). MT Project at University of Innsbruck. Meta, 37(2),

302-315. https://doi.org/10.7202/004620ar

\section{Résumé de l'article}

Ce compte rendu s'inscrit dans le cadre d'un projet de recherche ayant pour objectif une comparaison entre traduction automatique et traduction humaine. Un exemple de traduction (allemand-anglais) effectuée par un programme interactif est examiné et comparé à la traduction faite par des étudiants-traducteurs. Le texte choisi, un texte technico-commercial relativement simple, est d'un type réputé apte à la traduction automatique. Les difficultés les plus fréquentes rencontrées par la traduction automatique aux différents niveaux linguistiques sont commentées, et les aspects essentiels d'une traduction dont le traducteur humain peut tenir compte mais non la machine évoqués. 


\title{
MT PROJECT AT UNIVERSITY OF INNSBRUCK
}

M.J. WORMWOOD

University of Innsbruck, Innsbruck, Austria

\begin{abstract}
Résumé
Ce compte rendu s'inscrit dans le cadre d'un projet de recherche ayant pour objectif une comparaison entre traduction automatique et traduction humaine. Un exemple de traduction (allemand-anglais) effectuée par un programme interactif est examiné et comparé à la traduction faite par des étudiants-traducteurs. Le texte choisi, un texte technico-commercial relativement simple, est d' un type réputé apte à la traduction automatique. Les difficultés les plus fréquentes rencontrées par la traduction automatique aux différents niveaux linguistiques sont commentées, et les aspects essentiels d'une traduction dont le traducteur humain peut tenir compte mais non la machine évoqués.
\end{abstract}

\section{INTRODUCTION}

At the Department of Translation and Interpretation of the University of Innsbruck, Austria, work is continuing on a two-year project to compare both the process and results of machine translation to those of human translation. The language pairs being studied are German-English, English-German and English-French. Human translation is performed by students in translation classes, where all questions, difficulties, suggestions, etc., and of course the final translation(s) are recorded. The students are not given the texts beforehand, so they have made no written preparations for the class. This is done in the hope that they will verbalize at least some of the processes going on in the mind of the translator during translation.

MT is performed by the ALPSystems interactive translation program installed at the university, and all questions asked during interaction and the final results are recorded.

This article is not meant as a comprehensive translation criticism of either the machine or human translation. It will deal with the concrete results achieved during actual use of the MT program and not with its theoretical foundations. Some of the differences between MT output and the results of human translation will be illustrated. Certain examples are discussed in some detail in order to demonstrate the complexity of many of the problems that a machine translation program would have to solve to produce a translation worthy of that name.

Examining how the computer program deals with this text (which was translated during the one and a half hour class and is part of a longer text) will provide a better indication of the type of translations a computer will produce than merely examining individual phrases or sentences, as is commonly done when the output of MT systems is discussed. This tendency is, of course, very much in the tradition of structural linguistics, but it does not do justice to the realities of translation where texts and not just individual sentences are translated. An explanation of how one or two individual source text sentences are parsed and individual target language sentences synthesized by an MT 
system cannot be considered a demonstration of how the system translates a text, since a text is known to be much more than merely the sum of its individual sentences.

One further practice which is prevalent among advocates of MT has also been avoided - namely the selection of a text for which the computer has apparently produced a tolerable translation. This text has thus not been chosen because the results of the machine translation are particularly flattering to the MT system. Nor was it selected because the MT system produced exceptionally poor output. This technical and commercial source text is part of an annual report published by a German corporation. Both companies marketing MT systems as well as researchers in the field claim that texts of this type (as well as most other types) are amenable to translation by computer. ${ }^{1}$

The human translation of this particular text was performed by third and fourth year students of translation, for all of whom English is a foreign language. The instructor, a native speaker of English, directed the course, answered questions, offered advice, and at times provided suggestions.

Many supporters of machine translation reject a judgement of the quality of a translation, because it is impossible to assess objectively. Among the criteria they have put forward to replace that of quality are "readability", "informativeness", "intelligibility", "acceptability", "reading comprehension", "comprehensibility", "clarity", "usefulness", etc.

A major objection to these proposals is that they are not criteria for assessing a translation in particular - they could be used to judge any text at all. They do not refer to the relationship between the source and target texts, so their usefulness in this context is obviously greatly limited. Furthermore, these concepts are no more objective than that of quality which they are meant to replace.

This issue of translation quality should not be sidestepped. It may not be possible to judge the decisions made by the translator in producing a translation with total objectivity, but this does not mean the choices and decisions made during a translation can be considered arbitrary. Although absolute objectivity cannot be achieved, intersubjectivity can. The translator has reasons for making certain choices during a translation and these can be discussed and explained.

As for intelligibility, clarity, readability, etc., MT output often leaves much to be desired — as will be seen below.

\section{GERMAN SOURCE TEXT}

${ }^{1}$ Wir blicken gemeinsam auf die Leistungen und Ergebnisse eines erfolgreich verlaufenen Geschäftsjahres zurück. ${ }^{2}$ Es eröffnen sich für die Zukunft neue vielversprechende Perspektiven. ${ }^{3}$ In einer auf Vertrauen beruhenden Partnerschaft mit den Mitarbeitern liegt auch im neuen Geschäftsjahr ein wesentlicher Schlüssel zum Unternehmenserfolg. AUSBLICK

${ }^{4}$ Nach außergewöhnlichen hohen Vorleistungen geht XYZ mit Zuversicht und Selbstvertrauen in das neue Geschäftsjahr.

${ }^{5}$ Die Nachfrage nach informationstechnischen Produkten und Lösungen wird besonders auch unter Berücksichtigung der gesamtwirtschaftlichen Situation, in nahezu allen Märkten und Anwendungsbereichen zunehmen. ${ }^{6} \mathrm{Ziel}$ von $X Y Z$ ist es, diese Nachfrageimpulse aufzunehmen und in weiteres Unternehmenswachstum umzusetzen.

${ }^{7}$ Weltweit setzt sich der Trend zur Integration von Datenverarbeitung und Nachrichtentechnik fort. ${ }^{8}$ Entsprechend der Ausrichtung, als Generalunternehmer für informations-technische Lösungen tätig zu sein, wird XYZ auch künftig seine international 
führende Position bei der Integration von Informations- und Nachrichtentechnik zu anwendungs-orientierten Gesamtlösungen weiter ausbauen.

${ }^{9}$ Die Basis des angestrebten Wachstums in angestammten und neuen Märkten bilden unsere Finanzstärke und die hohen zukunftsgestaltenden Investitionen, die Internationalität, technische Kompetenz sowie unsere Kundennähe und Dienstleistungsorientierung. ${ }^{10}$ Unser Ziel ist es, auch 1988 ein über dem Durchschnitt der Branche liegendes Unternehmenswachstum zu erzielen.

\section{HUMAN TRANSLATION}

${ }^{1}$ Together we look back on the achievements and results of a successful business year. ${ }^{2-3}$ For the future we also see new and promising perspectives, with the key to the success of the enterprise to be found in our partnership with and trust in our staff.

\section{OUTLOOK}

${ }^{4}$ After having made particularly high investments last year, XYZ is confident and optimistic about the new business year.

${ }^{5}$ The demand for information technology products and solutions will increase in almost all markets and fields of application, particularly in view of the overall economic situation. ${ }^{6} \mathrm{XYZ}$ is anxious to meet this demand and thus achieve further growth.

${ }^{7}$ All over the world there is an increasing tendency to integrate data processing and telecommunications. ${ }^{8}$ In keeping with our policy of being a general contractor for IT products, XYZ will continue strengthening its leading international position in the field of integrating information technology and telecommunications engineering to offer useroriented products and systems.

${ }^{9}$ We are confident that our growth targets in established and new markets will be achieved on the basis of our financial strength, the high investments we have made in shaping our future, our international approach, and our technological competence, together with our close customer contacts and our service-orientation. ${ }^{10}$ Our aim is to achieve a growth rate in 1988 that is again above the average for the branch.

\section{MACHINE TRANSLATION}

${ }^{1}$ We look back on the achievements and results of a successfully passed financial year together. ${ }^{2} \mathrm{New}$ promising prospects present themselves for the future. ${ }^{3}$ In a partnership being based on confidence with the staff, a significant key to the company's success is also in the new financial year.

\section{OUTLOOK}

${ }^{4}$ After unusual high investments goes $\mathrm{XYZ}$ with confidence and self-confidence into the new financial year.

${ }^{5}$ The demand after information technology products and solutions becomes especially also lower consideration of the overall economic situation, in nearly all markets and field of applications increase. ${ }^{6} \mathrm{Goal}$ of $\mathrm{XYZ}$ is it to receive this demand and to turn into into farther growth.

${ }^{7}$ World-widely the tendency toward the integration of data processing and telecommunications continues. ${ }^{8}$ Following the orientation to be as general contractor for IT solutions active, becomes XYZ also future its internationally leading position at the integration of information- and telecommunications to application specific comprehensive solution farther expand.

${ }^{9}$ The bases of the strived for growth in traditional and new markets constitute our financial strength and the high future-shaping investments, the international philosophy, 
technical competence as well as our close customer contacts and service orientation. ${ }^{10}$ Our goal is it to achieve also 1988 an above average the line of business being growth.

\section{MORPHOLOGY}

At the morphological level, this MT system, like most, has relatively few problems correctly analyzing SL text and synthesizing TL text. Yet certain problems have not yet been solved. One involves the formation of English adverbs. If a German adverb is not included in the dictionary, but the corresponding adjective is, the program automatically forms an English adverb by appending -ly to the English adjective. Although this ad hoc routine sometimes leads to acceptable results, it also frequently produces inexistent words. In sentence 7 of the source text, for example, "weltweit" is used as an adverb. The dictionary contains the adjective "weltweit" and one possible English translation "world-wide". Thus, the supposed English adverb "world-widely" is formed during translation. ${ }^{2}$ When the entire sentence has been translated and the user sees that the program has created this type of word, he could, of course, enter the dictionary to add this German adverb and possible translations, and then restart the machine translation of the sentence, or he could edit the MT output for this sentence. It is nevertheless interesting to note that this MT system forms adverbs which do not exist.

An interesting morphological problem encountered by the program is demonstrated in sentence 8. The German reads "...bei der Integration von Informations- und Nachrichtentechnik...". To the reader it is obvious that the author is referring to "Informationstechnik und Nachrichtentechnik", but computer analysis does not go far enough to establish this fact. It considers "Informations-" to be an independent word, so although "Informationstechnik" is included in the dictionary, this entry is not found during translation.

There is another problem involving German compound nouns, namely the fact that they can be formed very easily. Many of these may be unique and will presumably never be seen again. In contrast to other programs, this one does not attempt to analyze compound nouns in the source text, so that even if the components of the compound are known, no attempt is made to "guess" the possible translation. (This method, used by other programs, will obviously often result in absurd translations). This type of compound noun appears in sentence 6 of the German source text - "Nachfrageimpulse". This term would not be found in any other dictionary, but would have to be included in the machine dictionary or the translator will be asked to supply a target language equivalent during translation. Since this source language term is a noun, the semantic information it contains must be expressed by a noun in the translation as well, i.e. a class shift is not possible. This rigidity of MT systems, which will be discussed again below, is one of the major handicaps to the machine translation of texts.

\section{LEXICAL ITEMS AND SEMANTICS}

If a dictionary entry includes just one possible translation for a source term, there is no interaction. If, however, there is more than one target language term in the bilingual dictionary, the user is able to select the desired translation each time the source term appears in the text. This feature replaces the so-called semantic analysis that most batch programs now perform and, in general, leads to better results in the selection of TL terms, although the amount of time spent answering the vocabulary questions can be quite extensive. If the dictionary does not contain the desired target language term, the user has the option of directly accessing the dictionary from the translation to modify the entry. Because of these features, this interactive program is able to avoid some of the semantic 
difficulties encountered by batch programs and many of the mistakes they continue to make despite the use of "semantic rules" (which sometimes do not actually involve semantic analysis but are merely rules of collocation. ${ }^{3}$ )

The ALPSystems interactive program, however, does encounter other semantic problems which could possibly be avoided by the semantic rules of a pure MT system. One such example is offered by sentence 3 in which the prepositional phrase complements with "in" are confused (see VERBS).

If the meaning of a term or phrase as it is used in a specific context differs from the lexical meaning(s), the additional features of an interactive program are of no help to the translator and this program does not perform any better than batch systems, since it would be impossible to include in the dictionary a translation for every conceivable contextual meaning. The translation of "aufnehmen" in sentence 6 is a good example of this, since the TL verb proposed by the student group for this context - "meet" - does not correspond to any of the common equivalents of "aufnehmen" and is therefore not included in the dictionary. All the various translations in the machine dictionary proposed during interaction (receive, pick up, take up, admit, include, hold, take down, photograph, record, take out) would be wrong in this context. This problem is quite common and is one of the numerous obstacles to better MT output.

As this example shows, it can still be impossible to achieve an adequate machine translation even though the machine dictionary may be excellent. There are numerous other obstacles as well. The human translation group, for example, made extensive structural changes to express the same meaning as the source text, but the procedure of the MT program - with very few exceptions - is to replace one lexical item in the source language with another lexical item of the same class in the target language. This rigidity is another of the major causes of poor to useless MT output and examples of it are apparent in the translations discussed below.

\section{SYNTAX}

Even at the syntactic level, which is easier to formalize and thus easier for the computer to deal with than other elements that have to be considered in a translation, this program, like all operative MT systems, is unable to correctly analyze some of the most common constructions, in this case in German. For this and other reasons, it often produces translations which are difficult to understand, unintelligible, or understandable but misleading or wrong. This is true of the majority of sentences in this translation.

An example of one construction over which this program inevitably stumbles can be seen in sentence 9. This sentence begins with an accusative object - a common phenomenon in German. A parallel construction would obviously be incorrect in English, but the MT output nevertheless starts "The bases...". This has, however, become the subject of the English sentence. Evidently, the program simply switched the arguments of the German verb "bilden" and made the subject (unsere Finanzstärke und...) the object (Die Basis...) and vice versa. Equally, a dative object at the beginning of a sentence or clause is a construction this program cannot deal with correctly.

Additional syntactic problems will be dealt with in the sections below.

\section{DETERMINERS}

As even the most basic comparison of English and German will demonstrate, there are many occasions on which an article is appropriate in English but not in German or vice versa. These differences are not taken into consideration by the program for this language pair, since both definite and indefinite articles or the lack of an article in 
German are rendered in precisely the same way in the English translation. Sentence 8 in German, for instance, reads "...als Generalunternehmer...", and the English translation "... as general contractor..."; the human translation, however, uses an indefinite article " $a$ general contractor." Another example is found in sentence 6. If the structure of the machine translation were to be retained, "goal" would require an article, and the MT output is plainly incorrect - "Goal of XYZ is...". These are just two examples of an error which is very common in MT output but one which could be easily corrected during post-editing.

Furthermore, there is a related problem which an MT system would have far greater difficulty handling. There are many instances in which it is best to use an English possessive pronoun for a German article. Instances can be found in this text in which the machine translation, like the source text, uses an article, whereas the human translation changes this to a possessive pronoun - which is clearly more idiomatic usage in English. This is the case in sentences 3 (our partnership, our staff), 8 (our policy), and 9 (our growth targets, our international approach, our technological competence). Although in all these examples the first person plural pronoun was used, the choice of possessive pronoun in each instance will depend on pragmatic factors (who is saying what to whom in the text), so no purely syntactic rule could be written to automatically effect this transformation.

These types of changes - the addition or deletion of an article, or the transformation of an article to a possessive pronoun - are corrections which would be relatively easy (and tedious) for a human revisor of MT output to perform, since they are some of the simplest errors made by the MT system. The following problems are more complex.

\section{PREPOSITIONS}

Despite the fact that the interactive program provides a list of English prepositions from which the user is asked to choose the translation of each German preposition, the one needed in a specific context is frequently not contained in this list. In order to include all possible one-to-one translations for each German preposition, every dictionary entry would need to contain a great number of TL possibilities; this would make them extremely unwieldy and make answering all the interactions for prepositions an even more tedious process. But this is not the major difficulty encountered by the computer program in the translation of prepositions. The major weakness, as so often, is the rigidity of the system.

In sentence 8 , the user had the choice during interaction of selecting "at" or "with" as a translation for "bei". In this particular instance, however, if a preposition alone were to be selected, "in" would be a better translation. If the user were to include in the dictionary all the prepositions most commonly used to translate "bei", this dictionary entry would contain perhaps fifteen English prepositions, making it very unwieldy. The same is true of other propositions as well.

But as this particular text example demonstrates, it is not merely a matter of replacing each German preposition with an English preposition, since structural changes may often be required. Therefore, having a long list of possible TL prepositions will not necessarily contribute toward achieving an adequate translation. In this case, the students used the prepositional phrase "in the field of" for "bei" and a verbal noun (integrating) which does not belong in the dictionary - for "Integration".

There are numerous possibilities for translating the German preposition "bei" into English. A preposition alone can often be used: by, at, near, beside, in, with, among, on, 
during, etc. Sometimes a prepositional phrase is a better solution: on the occasion of, in the course of, in the event of, in view of, etc. Furthermore, it may sometimes be necessary to introduce a subordinate clause in English, such as: "bei Regen" - "if it rains", "bei Gelegenheit" - "if/when the occasion arises", etc. 5 It is clear that this MT system cannot do justice to the complexity of translating this German preposition (and others) into English, since structural changes are often necessary but the program is incapable of performing them. This is a serious failing for an MT system, since the preposition "bei", for example, is very common in technical and scientific texts - the very kind of text which is said to be particularly amenable to machine translation. ${ }^{6}$

The user can enter combinations of verb plus preposition into the dictionary, and the program will often recognize these in a text. However, the greater the distance between the first and second elements, the greater the probability the program will not recognize that they belong together. In the German-English version of the program (but, unfortunately, not in the English-German version), it is also possible to enter a nounpreposition combination, which can reduce the number of interactions for prepositions, but the program has difficulties recognizing such a combination, especially if the preposition does not immediately follow the noun. In sentence 5 of our sample text, the program did not recognize the combination "Nachfrage nach", although this was included in the dictionary, and the preposition immediately followed the noun.

Furthermore, the program can incorrectly analyze the source text and arrive at an erroneous noun plus preposition combination, e.g. "confidence with" in sentence 3.7

\section{ADVERBIALS}

One of the most common errors the program makes with adverbials is their incorrect positioning in the translated sentence. This is dealt with in the section entitled WORD ORDER.

The program also has problems differentiating between German adverbs and adjectives. One example of this is the error made in translating "künftig" in sentence 8 (due to incorrect parsing). This adverb is translated as "future", despite the fact that the dictionary entry includes a translation for both the adjective (future) and the adverb (in future). The program apparently incorrectly considers this adverb "künftig" to be an adjective. This is just one of the numerous mistakes made in the machine translation of this sentence, and added together, they render it incomprehensible. It is interesting to note that in this case too, the human translation group used a very different strategy to translate what is expressed in "..., wird XYZ auch künftig seine...Position...weiter ausbauen." Their translation - "XYZ will continue strengthening its...position..." has an entirely different syntactic structure, although the semantic content is at least nearly the same. Once again, this is something that this MT system could not even attempt.

\section{VERBS}

The difficulties encountered by machine translation programs in dealing with verbs are numerous and, like all other problems, vary according to the language pair. In German-English translation, these include problems with tense and aspect, agreement between verb and subject, voice, mood, modal verbs, auxiliaries, participles and participial constructions, reflexive verbs, valency, separable German verbs, position of verb as well as semantic problems which, naturally, are not limited to verbs.

Some of the problems of tense and aspect encountered by batch MT systems can be avoided by the interactive program because it features a set of "switches" which, in the 
German-English version, allow the user to select the way two German tenses are translated into English. The German "present perfect"8 can be translated as "preterite"9 or "perfect"10, and the present tense as "non-progressive" or "progressive". Theoretically, these settings could be changed for every sentence, but apart from being tedious and time-consuming, it would mean that before starting the translation of each sentence, the translator would have to analyze it to ascertain the tenses and aspects to be used in the translation of that particular sentence. Hence, these "switches" are set at the beginning of a translation on the basis of the translator's judgement of the tenses / aspects which will presumably be needed in the entire translation.

The system also has other problems with tense and aspect. In sentence 3 of the sample text, the German present participle "beruhend" is translated as "being based", although it should be obvious that the progressive aspect is incorrect in this case. As can be seen, the students have rearranged this entire sentence, combined it with the previous one, and used a different verb and verb form for "beruhend". None of these translation strategies - the combination (or splitting) of sentences ${ }^{11}$ or the use of an entirely different verb and verb form - could even be considered during the machine translation of this sentence.

The verbs in sentences 5 and 8 of the machine translation both demonstrate the same weakness of the system - a weakness which leads to serious errors and makes these sentences difficult if not impossible to understand. In both instances, the auxiliary "werden" is analyzed as a main verb, namely "become", apparently because the auxiliaries are so far removed from the main verbs and machine analysis is merely local. As is the case here, the MT system often encounters insurmountable difficulties in correctly analyzing a sentence or clause if the source text does not follow the simple subject-predicate-object model, a sentence structure which is, however, less common in German than in English.

A semantic problem with the choice of verb is apparent in sentence 4 of the machine translation in which "gehen" is translated as "go". "Go" seems too concrete to be used in this context. A company does not "go into" a new year in English in the sense it can in German, although it might "enter" the new year.

In sentence 6 , the repetition of the preposition "into" following "turn" is due to the fact that the dictionary entry is "umsetzen - turn into" instead of "umsetzen in (plus accusative) - turn into". If this were corrected, the preposition "into" would not be repeated and the machine translation would read "...and to turn into farther growth." This translation still presents an interesting problem of verb valency, since the English sentence says that XYZ will turn into farther growth, which, obviously, does not make sense. In the English translation, unlike in the German source text, the object of the second verb (turn into) must be repeated even though it is the same as that of the first verb (receive), so this argument must be added to the translation, and the computer program is incapable of this. If it is not added, the trivalent prepositional verb (XYZ turns demand into growth) is misunderstood as a copula (XYZ turns into growth).

Even if this error were corrected, there are still semantic reasons for not choosing the verb "turn into". It is once again instructive to compare the MT output with the human translation. In the students' text, demand is "met" and further growth "achieved" - idiomatic English formulations. The causal relationship between these two phrases is expressed by "thus", and the result is: "XYZ is anxious to meet this demand and thus achieve further growth." Operational MT programs are nowhere near being able to produce results like this, even for such short sentences.

The third sentence of the machine translation also presents a valency problem, since it appears to state that the new financial year is a key to the company's success. The 
analysis of the source text was incorrect, i.e. the program did not recognize which of the prepositional phrases with "in" was the obligatory complement ("in einer auf Vertrauen beruhenden Partnerschaft") and which was the optional adverbial (im neuen Geschäftsjahr). And in synthesizing the English sentence, the program did not recognize that the prepositional phrase complement in this instance cannot be temporal - the "key" cannot be in a year.

A further related aspect, which would be incomparably more difficult for an MT system to handle, is the fact that the subject in English sentences tends to be more concrete than in German. If the choice of subject in the target text differs from that in the source text, this obviously has implications for the choice of verb. Sentence 2 is a good example of this and is dealt with in the section entitled CHOICE OF SUBJECT.

\section{STRUCTURAL CHANGES}

The inflexibility of the system becomes a major handicap when the translator would like to make a class shift in passing from SL to TL. This G-E interactive program is capable of carrying out a very limited number of structural changes, but it can still be said that its output is basically a translation of one word or phrase after another with a minimum of resorting of word order (very often incorrect). This MT system, like others, does not translate meaning but just a series of individual words (and phrases). This problem is a major one for this program in all types of translations - even the translation of scientific and technical texts which are often claimed to be particularly suitable for MT.

One common structural change in German-to-English translation is the use of a verb or verbal noun for a German prepositional phrase. This technique was used by the human translators, for instance, in sentences 4,7 and 8 . Sentence 4 , translated by the computer as "After unusual high investments goes XYZ with confidence..." is not immediately understandable in English unless a verb is used, such as in the non-finite clause used by the human translation group - "After having made particularly high investments last year, XYZ is confident...". The addition of "last year", which is understood in the German, also improves the clarity of the English sentence. Obviously, currently available MT systems could not add this type of clarification, since at no point during the "translation" is the text "understood".

Sentence 7 of the machine translation is understandable, but the nominal style "the tendency toward the integration of data processing and telecommunications continues" - is more typical of German than of English. The human translation, in contrast, uses an infinitive construction for "Integration" - "there is an increasing tendency to integrate data processing and telecommunications" - which is a great improvement over the MT version.

Sentence 8 of the machine translation, which is not understandable due to a combination of various errors, uses a construction for the prepositional phrase which is parallel to the German - "...its internationally leading position at the integration of information- and telecommunication...". This prepositional phrase was translated by the students with the help of a verbal noun in English - "... its leading international position in the field of integrating information technology and telecommunications engineering...".

\section{PRENOMINAL PARTICIPIAL CONSTRUCTIONS}

This is an example of a common German construction which in many cases very obviously cannot be translated into English using a parallel construction. An excellent example can be found in sentence 10 of the sample text. It is safe to say that no human 
translator would even consider using a construction parallel to the German "ein über dem Durchschnitt der Branche liegendes Unternehmenswachstum". Yet that is exactly the solution the MT program offers here, since it translates: "an above average the line of business being growth". In contrast, the students used a relative clause - "...a growth rate in 1988 that is again above the average for the branch".

Use of a relative clause or a postnominal participial are techniques which are regularly used to translate German constructions of this type into English. Yet like any translation technique based on syntax alone, this cannot be considered a hard and fast rule. As can be seen in the human translation of sentence 3 ("In einer auf Vertrauen beruhenden Partnerschaft mit den Mitarbeitern"), other constructions may also be appropriate ("in our partnership with and trust in our staff"). Since such changes are also dependent on semantics and context, their formalization in a program cannot be based solely on syntax.

The only prenominal participial construction in our text which was recognized as such and for which a structural change was attempted by the MT program was the one in sentence 3 . The verb form chosen for the translation - continuous aspect - , however, is incorrect, and the relation to the prepositional phrase "mit den Mitarbeitern" was incorrectly analyzed - the German is obviously referring to the company's partnership with their staff and not their confidence "with" their staff. This is an example of MT output which may be "understandable", but is nevertheless wrong.

Sentence 1 of the German text also uses a participial construction - "erfolgreich verlaufenes (Geschäftsjahr)". This is rendered by the computer as "a successfully passed financial year", which is "understandable" and "readable", but, unlike the human translation ("successful financial year"), not idiomatic English.

The longer these constructions become, the lower the chances they will even be understandable in an English translation using a parallel construction, and since they are far from uncommon in German, an MT system should have routines to dependably recognize and deal with them. In our sample text, none of the translations for constructions of this type were correct.

\section{WORD ORDER}

In addition to the numerous structural mistakes due to false source text analysis or target text synthesis, the program seldom produces an English sentence in which the word order is correct. And even when it is grammatically correct or nearly so, the functional sentence perspective is never taken into account, since this type of intersentential consideration is not seen by the MT system as part of the translation process.

In the machine translation of our sample text there are numerous examples of incorrect word order. In fact, English word order is usually very nearly parallel to the German, although the regular attempts to place the English verb in the correct position do constitute an exception. Yet even these attempts are often unsuccessful. In sentence 4, the verb and the subject in the TL text are inverted, just as they were in the source text. This is obviously German and not English word order, but errors of this type are frequent. The final position of the verb in sentence 5 of the machine translation is also the same as the German position, and, partly due to numerous other errors, it is not even clear what increases. In this sentence the program has retained the exact word order of the source text sentence, a strategy which seems to be used when analysis proves too difficult, but whose results, as can be seen in this example, are usually far from satisfactory.

The beginning of sentence 6 was also translated word for word with no rearrangement of word order, and the results are incorrect, although perhaps 
"intelligible". The word order of the rest of this sentence is correct, but the meaning of the sentence as a whole remains unclear for other reasons. In the text produced by the students, the result is a great improvement over MT output, since the message and not the individual words were translated. Although this German sentence (6) is short and its syntactic structure relatively simple, it proved impossible for the computer program to produce an idiomatic English translation of it. Nor is the human revisor of MT output much closer to a final translation than he was before the machine translation of the sentence. In this case too, it seems that MT output would only be confusing to the translator, and correcting it to arrive at an adequate translation would be more timeconsuming than starting with the German source text.

The position of adverbs is regularly incorrect in the MT output. By way of example, the position of the machine translation for "auch" is incorrect in every instance it occurs in the translated text - in sentences $3,5,8$ and 10 . It sometimes seems that the correct positioning of an adverb is mostly a matter of chance.

\section{CHOICE OF SUBJECT}

The preference of the German language for more abstract subjects than English is an aspect that must be taken into consideration when translating between these two languages. In the human translation of this text, there are examples of a change from an abstract subject to a personal subject. By comparison, a change like this cannot even be considered by the MT system.

In sentence 9, the subject of the German sentence is "unsere Finanzstärke und die hohen zukunftsgestaltenden Investitionen, die Internationalität, technische Kompetenz sowie unsere Kundennähe und Dienstleistungsorientierung". First of all, this English sentence cannot start with the accusative object as does the German sentence (and the machine translation $)^{12}$. In addition, the students decided that the English sentence should have a personal subject - "we", which is a logical and obvious choice for the translator who has understood the text, even though it is not explicitly mentioned in the German sentence. This change is inconceivable for the MT system.

Sentence 2 in German uses "es" as the subject. The MT program correctly recognized that a parallel construction would be incorrect in the English sentence, but it uses "the new and promising prospects" as subject, whereas the human translation introduces the personal subject "we" which, once again, is not explicitly mentioned in the source text but is nevertheless an obvious choice. Here too, the abstract "prospects" is a poor choice of subject.

In the machine translation of sentence 7 , the subject is the equivalent of the abstract noun used in the German source text - the tendency. This translation contrasts with the introduction of "there is" in the human translation, which makes it possible to avoid the abstract subject and also serves to introduce the new information in this sentence, since it appears incongruous to speak of the trend (definite article) despite the fact that this idea has not yet been mentioned. This too is a textual consideration which is entirely alien to the machine translation program, but nevertheless necessary to improve translation quality.

Another abstract German subject used as the subject in the machine translation but not by the students is "Ziel" in sentence 6. The computer produced "Goal of XYZ is it to receive...", whereas the human translation reads "XYZ is anxious to meet...". This change and the numerous other pitfalls avoided by the students but not by the computer program lead to a translation which is far superior to the MT output. The meaning of "Ziel" in this context was expressed in English by means of a predicate adjective - 
"anxious", and although other suggestions can no doubt be made for the translation of this sentence, what is interesting to note, once again, is the principle that although numerous structural changes may be required, they are usually impossible in a machine translation. This rigidity is one of the major weaknesses of MT.

\section{FOCUS}

As was mentioned above, the position of the information in a sentence in not even considered by the machine during translation, so MT output is usually inferior to human translation in this regard. By contrast, the human translation group often discussed this aspect at length.

If we study just the first paragraph in this text, examples of this type of error can be seen in every sentence of the MT output. In sentence 1, the final position of "together" in the machine translation gives this adverb more prominence than is intended by the author of the German text, and thus distorts the message of the sentence. In sentence 2-3 of the human translation, "for the future" is placed at the beginning of the sentence to give it contrastive focus, since it contrasts with the past year dealt with in sentence 1 . In the machine translation, however, this adverbial is put the end of the sentence and the contrastive focus is lost. And finally, the initial position of the prepositional phrase complement in German sentence 3 ("In einer auf Vertrauen beruhenden Partnerschaft mit den Mitarbeitern") places the focus on this information. To achieve a similar emphasis in English, the student group placed this information at the end of the sentence, which is the neutral position of focus in English. The machine translation begins the sentence just as the German sentence begins, and the result is not grammatical. These few examples demonstrate that a revisor of MT output would have to spend a good amount of time correcting this type of error as well.

\section{SOURCE TEXT ERRORS}

An error in the SL text is something that cannot be taken into account by the MT system, but can, however, be improved in a human translation. A minor example of this type of error is evident in sentence 4 of the German text "Nach außergewöhnlichen hohen Vorleistungen...". The author clearly meant that the investments were unusually high, and not that the investments themselves were unusual, i.e. the adjective "außergewöhnlichen" should have been an adverb - "außergewönlich" — modifying "hoch". The human translation group did justice to the author's intentions and corrected this mistake in their translation, but the MT output of course makes the same mistake as the author of the German text. Since it is commonplace for the translator to be confronted with a faulty source language text, the importance of this aspect should not be overlooked.

\section{CONCLUSION}

The difficulties encountered by the MT program differ greatly from those discussed by the human translation group, and most of these in turn were not even considered by the MT program.

Although many of the aspects discussed above are dismissed by proponents of MT as merely stylistic considerations, ${ }^{13}$ they cannot be ignored. Even in a machine translation which only serves "rapid information purposes", these errors, when combined and added to the other mistakes made by MT systems, can easily make a text or parts of it at best difficult to understand, and, at worst, incomprehensible. 
The program considers nothing but morphology and syntax in "translating" a text (the choices between lexical items are made by the translator), but there are still certain morphological and numerous syntactical mistakes in this short sample text. Many common German structures are not recognized during analysis and what is produced during synthesis is rarely grammatical English. Furthermore, the full range of errors made by the program in German-to-English translation includes many more that were not seen in this translation. Word order in the machine translated English text usually closely follows German word order and is sometimes exactly the same. This contributes to making some output unintelligible.

Because the program is interactive, some of the lexical and semantic problems encountered by batch systems can be avoided, so its output is often an improvement over that of certain batch systems. The time factor, however, should also be taken into account, and an interactive system of course requires a far greater amount of time to perform the raw translation than a batch system. This program too, however, can only take lexical meaning and not contextual meaning into account.

Most relations between elements in a text apart from morphology and syntax must be ignored by the MT program, since it would be far too complex to formalize what a human translator does when analyzing these relations and taking them into account when producing a translation.

A fundamental fault of this program is the assumption that translation consists mainly of replacing each lexical unit in one language with a lexical unit in another. Apart from a few superficial modifications, no structural changes are possible, i.e. the meaning of a clause or sentence in the SL must be rendered with the same parts of speech in the TL.

If this MT output were to be used only as a rough first translation, the translator would still not be much closer to the type of translation produced by the human translation group than he would be if he had just the German source text. Someone must still analyze and understand the source text on all levels (not just morphologically and sometimes syntactically) before an adequate translation can be achieved. To state or imply that this job can be done by the computer and that MT output need only be revised like any human translation is at best misleading, although this is an argument which is frequently put forward by proponents of MT. ${ }^{14}$ This MT output contains so many mistakes of all kinds that there is rarely a sentence which would be considered acceptable if it were produced by a human translator - even in a first draft translation.

MT has long been used to translate syntax-controlled, domain-specific texts (TAUM-METEO, TITUS). It has also long been used to produce output for "rapid information purposes" or "information scanning", although the percentage of recipients making such lenient demands on TL texts is relatively small. ${ }^{15}$ As for this MT program, it is certainly debatable whether the output it produces even deserves to be called translation, since most of what is considered by the human translator during translation is simply ignored by the machine, and so much of what it does attempt turns out wrong.

Notes

1. Kingscott, for instance says of company reports and other financial texts: “...this sort of work would seem to lend itself to machine translation" (Kingscott 1989: 50). The same author says of technical translation that "this is a field which is well documented, and can be the most easily adapted to machine translation" (ibid.).

2. Before the text is translated, the program compiles a terms-to-add list (words not found) by comparing all the words in the text to the entries in the dictionaries indicated. Unfortunately, a term found in one of the dictionaries as an adjective, but used in the text as an adverb is not included in this list of terms to add. Therefore, the user has no way of knowing that the program will produce such nonsense adverbs as "worldwidely". 
3. This is the case with LOGOS, for instance.

4. Semantics, intersentential and textual considerations, pragmatics, convention, style, etc. are far greater stumbling blocks for MT systems, and in fact most of these are simply ignored.

5. In addition, there are numerous collocations with "bei". These could, of course, be added to the dictionary, which is not to say they would be recognized in a source language text and correctly translated (e.g. discontinuous phrases).

6. A survey of the possible translations of "bei" in technical and scientific texts is provided by R. Kraus (Lebende Sprachen), who demonstrates the complexity of translating such a seemingly simple word.

7. For a discussion of prepositional phrases, see STRUCTURAL CHANGES.

8. The German perfect tense is meant by this.

9. Here, the simple past tense is meant.

10. Means present perfect.

11. "Segments" to be more precise. A segment is any group of words ending with a period, question mark, exclamation point, colon, semicolon, or paragraph marker

12. See LEXICAL ITEMS AND SEMANTICS.

13. At one point Kingscott brushes aside critics of output from one particular MT system as mostly "pedantic teachers complaining about grammatical solecisms" (Kingscott 1989: 28)

14. See, for instance, Hutchins, pp. 166, 329-330.

15. The percentage of translations performed by SYSTRAN at the EEC Commission, for example, is quite small (1985: about $3 \%$ ), and these are mainly performed in cases where documents would not otherwise have been translated at all (Picken 1986: 175).

\section{BIBLIOGRAPHY}

BRINKMANN, K.-H. (1978): "Perspektiven der maschinellen Übersetzung," Sonderdruck aus, Nachrichten für Dokumentation 3, 104-108, Munich, Verlag Dokumentation Saur KG.

FRIEDERICH, W. (1987): Technik des Übersetzens: Englisch und Deutsch, 4th ed., Munich, Max Hueber.

HUTCHINS, J. (1986): Machine Translation: past present, future, Chichester, Ellis Horwood.

KINGSCOTT, G. (1989): Applications of Machine Translation - Study for the European Communities, Nottingham, Praetorius Limited, for the Commission of the European Communities.

KRAUS, R. (1978): "Die Präposition 'bei' in technisch-wissenschaftlichen Texten (D-E)," In Lebende Sprachen 1, 8-12.

LEHRBERGER, J. and BOURBEAU, L. (1988): Machine Translation: Linguistic Characteristics of MT Systems and General Methodology of Evaluation. Amsterdam/Philadelphia, John Benjamins Publishing Company.

LEISI, E. (1971): Der Wortinhalt: Seine Struktur im Deutschen und Englischen, Heidelberg, Quelle \& Meyer.

PICKEN, C., (Ed.) (1986): Translating and the Computer 7, London, Aslib.

REIB, K. (1971): Möglichkeiten und Grenzen der Übersetzungs-kritik: Kategorien und Kriterien für eine sachgerechte Beurteilung von Übersetzungen, Munich, Max Hueber.

REIB, K. und VERMEER, H. (1984): Grundlegung einer allgemeinen Translationstheorie, Tübingen, Niemeyer.

SNELL-HORNBY, M. (Ed.) (1986): Übersetzungswissenschaft - eine Neuorientierung: zur Integrierung von Theorie und Praxis, Tübingen, Francke. 